\title{
Digital Media in Archaeological Areas, Virtual Reality, Authenticity and Hyper-Tourist Gaze
}

\author{
Nicolò Costa ${ }^{1}$, Marxiano Melotti ${ }^{2}$ \\ ${ }^{1}$ University of Tor Vergata, Rome, Italy \\ ${ }^{2}$ University Niccolò Cusano, Rome, Italy \\ Email:n.costa@lettere.uniroma2.it, marxiano.melotti@unisu.it \\ Received June 27 ${ }^{\text {th }}$, 2011; revised October $2^{\text {nd }}, 2011$; accepted November $22^{\text {nd }}, 2011$
}

\begin{abstract}
The increasingly widespread use of digital media and "virtual reality" in archaeological areas seems to confirm the passage from the traditional tourist gaze to a new hyper-tourist gaze. Archaeological areas, incessantly re-presented in virtual reality, are already part of an a-geographical city, characterized by new kinds of flows. The "virtual reality" of archaeological areas helps to "mark" a new phase in the economic and cultural history of tourism. A comparative presentation of some important activities carried out in these areas and the forms of multimedia communication related to archaeological tourism illustrates this trend. Notwithstanding the sceptical or conservative attitude of many institutions, this use of digital media does not generate cultural perplexity in the general public, which instead seeks and rewards the most innovative initiatives that best combine entertainment and educational aspects.
\end{abstract}

Keywords: Archaeology; Authenticity; Digital Media; Edutainment; Museums; Tourism; Virtual Reality

\section{Introduction}

This paper argues that the increasingly widespread use of digital media and "virtual reality" in archaeological areas indicates a new trend: passage from the tourist "gaze" (Urry, 1990) to the hyper-tourist gaze. Archaeological areas, incessantly represented, or even re-invented (Melotti, 2011), in virtual reality, are part of an a-geographical city, connected by flows and mobilities (Sheller \& Urry, 2004; Hannam, Sheller, \& Urry, 2006) in which intensely polysensorial post-modern urbanism is experienced (Hunnigan, 1998; Costa, 2003; Costa \& Martinotti, 2003).

We will show that the "virtual reality" of archaeological areas and heritage preservation (Guttentag, 2010; Bruno et al., 2010; Guarnieri, Pirotti, \& Vettore, 2010) helps to "mark" a new phase in the economic and cultural history of tourism.

In the "logocentrism" of the Grand Tour, the journey was a serious and committed reflection, and it was narrated on paper by "journey literature", consisting of diaries and novels. The mid-19th century saw the development and success of photography, which increased the sales of tour operators. The flâneur was replaced by the sightseer of organized mass tourism (Adler, 1989). Hence, writing became more and more marginal with respect to photographs. Tourist and gaze were one and the same: no tourist was without a still or movie camera. This "oculocentric" tourist (Wang, 2000) re-lived heritage places with all his senses, within an experiential economy mediated by I \& C (information and communication) technologies (Pine \& Gilmore, 1999).

Today, in the relationships among visual culture, cultural tourism and hospitality economy (Crouch \& Lubben, 2003), the virtual image is used not only as a tool of information, communication and tourist promotion of the museum or archaeological area but also as a productive resource to invent new forms of business in museums and archaeological areas. They become containers of a new post-modern mix that transforms the cultural place into a tremendously serious type of "play" that hybridizes knowledge and scientific and humanistic skills in a new synthesis. The fact that the virtual image has neither the depth of authenticity (MacCannell, 1976) nor the extraordinariness of the romantic gaze (Urry, 1990) is not a problem. The tourist lives and seeks experiences that go beyond the traditional debate on authenticity or represented authenticity. The new experiential tourist of archaeological areas enhanced by digital media seeks "places in play", according to the dictates of the new culture of edutainment and emotions. This takes the form of a true cultural revolution: the tourist does not seek a "material" type of authenticity but is satisfied with the authenticity of experience and sensation. Virtual reality must no longer necessarily reconstruct spaces and environments, it must create leisure and emotions. In new archaeological sites enhanced by digital media, it is sufficient to create a sensation of authenticity.

However, this change of tourist demand is not matched by an adequate change of supply. This paper argues that it is necessary to adapt the latter by giving space to creative interventions characterized by new transdisciplinary skills able to combine education and entertainment, archaeology and digital media, culture and marketplace.

Our analysis is based on an inductive method, which goes from the detailed to the general, beginning with the comparative presentation of some important cases related to activities carried out in archaeological areas and museums (multimedia installations, special effect shows, sensory trails) and to multimedia communication in the same areas (guides and devices that reconstruct the places as they once were).

\section{A Complex Context}

The use of innovative tools for the enhanced use of museums 
and archaeological sites is extremely varied and reflects a plurality of needs and cultural orientations that demonstrate the essentially cultural difficulties with which archaeologists, administrators and professionals cooperate and tackle the relationships with the marketplace and tourism. In short, we can say that the new media are now widely used but in an extremely disorderly and random manner responding neither to coordinated policies nor to the set of best practices that several decades of experience should have consolidated by now. The best use of museums and archaeological areas is entrusted to the good sense, skills and often economic or political interests of local administrators. In the absence of coordinated policies and a shared theoretical framework, there is a tendency to follow the latest fashions and to conform to the requirements of financiers. The number and quality of interventions appear to be closely linked to the level of political and cultural metabolization of the relationship between public and private.

Some countries, such as the United Kingdom, Germany and the Scandinavian states, have now metabolized the relationship between public and private and have begun a serious scientific reflection on the relationships between protection and enhanced use, on enjoyment and education, and on the role of media and technologies (Swain, 2007; Clack \& Brittain, 2007). However, this relationship still seems extremely problematic in other countries, such as Italy, and the relationship between archaeology and the marketplace gives rise to lively debates with alternate results. Where market demands are perceived as degrading or dangerous to the supposed historical dignity of the patrimony, enhancement interventions tend to have an extremely conservative nature and the use of new technologies is relegated to extraordinary interventions, which become more socially acceptable if presented as "events". To this is added the extreme variability of the relationship between humanistic and scientific cultures, which in some contexts tends still to be perceived in dichotomous terms. The frequent distrust of humanists, and particularly of archaeologists, for the exact sciences (often reciprocated by students of the latter) has hindered a correct diffusion of methodologies of enjoyment and education based on the new media. Virtual reality has long been considered a type of "play" or an unscientific form of entertainment or, worse, a mere merchandising activity. On the one hand, this has limited academic thinking in this field; on the other hand, it has left the planning (and the fruits) of the first interventions to the private sector, which has hindered the formation of new collaborative and creative interdisciplinary professional skills. Moreover, we should not underestimate the low level of technological skills and resources that still characterizes almost all European cultural heritage institutions (Missikoff, 2006).

For at least two decades, European policies have been oriented toward a progressive integration of human and other sciences and, in recent years, have also been affected by the drastic decline of the former, partly due to funding cuts. This has significantly contributed to bringing many sectors of academic research closer together and relating them to the business world. However, it should be specified that tourism, and particularly archaeological tourism, has never been the object of specific European research funding. This has helped marginalize tourism in the ambit of large research projects. Thus, there has been a progressive integration of the human sciences (including archaeology) and the exact sciences (such as informatics), which has created the technical premises for new types of uses of museums and archaeological sites. Nevertheless, the "tourism sciences”, traditionally perceived as extraneous to both archaeology and informatics, have barely been touched by this process. Hence, virtual reality and multimedia systems have developed and spread in the absence of specific thinking about tourism or, in a wider sense, about the final users. Digital media created in academic or administrative circles were (and partly still are) conceived as an "offer" and not as "consumption"; as an output of the scientific communication of sites and museums and not as an expression of the new recreational requirements of users. In contrast, digital media produced outside of the academic world were (and are) conceived as pure entertainment and as a sophisticated form of merchandising. Above all, a reflection from the point of view of the consumer has only recently begun to take place: to put it in sociological and anthropological terms, a reflection on the new society of edutainment and on the new forms of relative authenticity.

This is the key point: notwithstanding the sceptical or conservative attitude of many institutions, the use of digital media in museums and archaeological areas does not generate cultural perplexity in the general public, which instead seeks and rewards the most innovative initiatives that best combine entertainment and educational aspects. In other words, although discussion on the concept of authenticity is still open in academia, the public, absorbed in the "liquidity" of post-modern society (Bauman, 2000), has already metabolized the cultural changes that scholars are still trying to place within a theoretical framework. The idea and practices of authenticity have been profoundly modified by a series of factors: the increased sharing at a global level of the same cultural reference systems; the loss of borders and the gradual erosion of the identity of social phenomena and cultural practices; the advanced digitalization of society, which already contains generations of "digital natives"; the loss of centrality of the historical and humanistic culture in European and North American schools and universities. In a digital society (in which the use of digital, virtual and multimedia systems and the creation of electronic contents are a mass practice), the relationship between original and copy can no longer be that of the old pre-digital society. The very concept of reproduction is completely innovative: not only does the copy seem like another original, there is no longer any sense in raising the problem of the difference between copy and original.

This implies a substantial change in tourism and cultural heritage sectors. The use of digital media in museums and archaeological areas is no longer perceived as a "violation" of the identity of the specimen or site, and the co-existence of authentic specimens, virtual reconstructions and multimedia systems is accepted. Indeed, for digital natives, it is a condition for understanding the context: in the absence of digital media, museums and archaeological areas are "undecipherable".

Paradoxically, we are witnessing an increasing discrepancy between the quality of the technological offer and the multimedia skills of the users. Throughout the 1990s, the various forms of virtual reality and the use of multimedia systems were able to amaze the public, helping to create an effect of "enchantment”. However, in the new millennium, the public remains increasingly dissatisfied with the technological quality of the offer.

From this point of view, the frontier of technology and technological satisfaction lies not so much in the offer of the devices and displays mounted in the sites and museums as in the set of electronic systems (now fully interconnected) that pre- 
pare and accompany the archaeological visit. These systems, which relate the visit not only to the rest of the tourism experience but also to the total life experience of the users, include internet sites, blogs, social networks, smartphones, geolocators, satellite navigation devices, electronic booking systems, rapid visualization systems, and the downloading and transfer of images and other electronic multimedia contents. Therefore, archaeological sites and museums are trying to adapt to the new panorama of mass digital use, supplementing the traditional offer of digital and multimedia displays with new interactive systems related to the new digital use practices: creation of discussion groups and forms of publicity on Facebook and Twitter; digital and increasingly three-dimensional photographic archives to be accessed online; interaction in situ and at a distance with smartphones. Large museums, like the Louvre or the British Museum, compete in creating fast and visually attractive web sites, which allow people to make virtual visits, to see three-dimensional reconstructions or short films with explanations, and obviously to buy merchandising.

\section{A New Kind of Authenticity}

An important element, which has significantly contributed to the success of what we might call the new culture of relative and relational authenticity or hyper-authenticity, is the new relationship with history and, more generally, with the past. The progressive loss of historical knowledge, related to a compression of teaching and a general simplification of humanistic education, makes the relationship with the past much more fluid and in some aspects more creative. A public with an increasingly less precise and knowledge-based education tends to more easily accept historical reconstructions aimed at offering emotions rather than "authenticity". This tendency should be seen as part of a general process of "immaterialization" of the demand, typical of the most advanced phase of the present consumer and image-based society: the public seeks sensory and emotional experiences and not necessarily content. Interest in the past is basically of an emotional nature: hence, it is no longer necessary to assure a material use of the past or to reproduce it materially; it is enough to create atmospheres and generate sensations.

Of course, this affects the use of sites and museums: a public increasingly less demanding in terms of historical precision prefers the proposal of emotional and sensory experiences. From this perspective, the educational aspects tend to give way to pure leisure aspects, justifying the worries of more conservative scholars. This has some immediate consequences on the systems of uses of sites and museums: on the one hand, we see initiatives such as living history and re-enactments, which manage to satisfy the demands of the public with limited costs and low technological levels; on the other hand, we see the diffusion of displays aimed at creating sensations rather than content via sounds, lights and projections. In a certain sense, we are witnessing a kind of technological regression of the offer, which tends not only to resemble the proposals of now distant phases of the history of modern tourism, such as the culture of "sound and light" shows of the mass tourism of the 1960s but also to re-propose the romantic and emotional approach of the Grand Tour of the early 19th century. However, all this occurs within the context of the new cultural tourism (Costa, 2005b; Melotti, 2011): a type of mass tourism, but carried out for small unorganized groups; not cerebral and not necessarily strong on content, yet demanding and sophisticated; concentrated on the traditional large destinations, but increasingly attentive to the innovative proposals of small centres; still considered a "separate" activity and represented as a "slow" practice, yet increasingly conducted in rapid, "distracted" and sometimes even unintentional forms combined with other not necessarily tourist practices; fully included in the culture of globalization and in the mechanisms of consumerism, but attentive to local identities; fascinated by history, yet also enchanted by shopping.

\section{The Challenge of Digital Media: Some Examples}

A number of cases help us to clarify the complexity, vivacity and inconsistency of the aforesaid tendencies. Pompeii is one of the most important and best known sites in which the traditional practices of archaeological mass tourism are mixed with the new forms of contemporary cultural tourism. With its 2.5 million visitors per year, Pompeii is one of the most visited archaeological sites in Italy and Europe, yet the number of visitors is lower than that of many amusement parks and shopping malls. Nevertheless, the administrators, who have trouble efficiently managing the site and complain about the poor sustainability of its tourism, seem satisfied. Despite the fundamentally traditional nature of its tourism offer, Pompeii remains a symbolic site for the entire country. Therefore, its administrators feel duty-bound to experiment (albeit without coordination or adequate studies) with innovative orientations that could provide an image of "modernity", while universities, research centres and private companies tend to exploit its world-famous image to obtain financing and sponsorships.

With regard to digital media, we should mention "Lifeplus" (2002-2004), an innovative project funded by the European Union as part of the IST program (Melotti, 2003). The aim of "Lifeplus" was to reconstruct, via augmented reality, spaces, buildings and scenes of daily life in ancient Pompeii to be seen in situ and in real time during the visit to the archaeological area. This project anticipated by several years the interest in less archaeological aspects of the visit and the tendency to spectacularize it with "events" and sensory activities. However, the state and local administrations failed to understand its innovative nature and did not proceed to its industrial and tourist implementation.

Indeed, because of its "complexity”, augmented reality has not been a success in archaeological sites and is now used essentially in museums. Relevant in this regard is the Hellenic Cosmos Interactive Museum of Athens (established in 1998), where, in the name of edutainment, high-quality virtual reality installations "recount” famous episodes of ancient history, such as the Battle of Thermopylae (presented in 2009).

Pompeii discovered the new sensory culture more recently. In 2009, in the middle of a financial and administrative crisis, it provided visitors with a "sensory platform" on which they could experience the impression of an earthquake and, according to its creators, relive the most dramatic moments of the catastrophe that destroyed the city. In this case, the technology did not serve to bring added value to the visit but simply to give a mental image of death and destruction that has historically underlain tourism at Pompeii. With the same logic, the administrators inaugurated adults-only night-time visits to the suburban thermal baths, famous for their erotic frescoes. Thus, digital media are used at Pompeii in a leisure form that seems to follow the sensory tendency of contemporary tourism, even if it 
resembles the traditional voyeuristic components that have long characterized tourism at the site.

The media visibility of Pompeii and its tourism success has naturally led to a proliferation of digital media for commercial uses: virtual reconstructions, computer games, audio-guides, etc. Without doubt, the most interesting initiative is the digitalization of Pompeii's roads by Google. This application is not only a significant step toward virtual archaeological tourism, carried out entirely at a distance, but also constitutes a small cultural revolution that restores Pompeii's specificity as a "city" to the archaeological site.

The situation is also very varied in terms of multimedia displays. With great foresight, Paestum established a small multimedia archaeological museum, the Narrative Museum of Hera Argiva (inaugurated in 2001), which does not display specimens but "recounts" the myths of the ancient city with voices and projections. The use of multimedia is an effective tool to make the most of the immaterial aspects of a culture, such as its myths. Also in this case, however, the unrealistic aspirations of the project must be underlined: the museum, not well publicized and poorly connected with the archaeological site, welcomes its few visitors with non-functioning projectors and defective loudspeakers. Virtual reality, when it only follows a political logic and is not included in a serious project for the use of the territory, remains too virtual.

In contrast, the multimedia display of the Roman villas discovered and turned into a museum in the underground areas of Rome’s Palazzo Valentini (2009) can be listed among best practices. Sounds and evocative noises, interplays of light and shadow, projections of images and virtual reconstructions superimposed on the remains, and the narrating voice of a famous television scientific journalist all create a visit that satisfies from both the sensory and educational points of view. The success of the Palazzo Valentini museum is partly due to it being "underground" and thus spontaneously associated with a dimension of "alterity" and mystery, in conformity with the emotional characteristics of the new cultural tourism. Yet, it also depends on the high technical quality of the installation and the unusual attention to the quality of the content and language. This demonstrates that it is possible to propose quality edutainment activities and that an adequately informed public is able to appreciate not only the leisure aspects of edutainment but also the educational aspects.

Displays of this type have the advantage of arousing interest in spaces that, by themselves, have low archaeological appeal and are not easily understood by non-specialists. In London, laser lighting creating human outlines and background noises that suggest the presence of an unruly public enhance the underground remains of a Roman amphitheatre, which otherwise would not merit a visit. The same occurs in Milan, where the few metres of wall of a Roman theatre present in a cellar could become the object of tourist visits thanks to sounds, multimedia projections and olfactory plates, which, according to the creators, release fragrances and odours that would have been perceived in an ancient theatre. The use of fragrances is perhaps the most cutting-edge of the technologies applied to visits to archaeological sites and museums. On the one hand, it responds to the "slow" demands of the new cultural tourism, which seeks immaterial and sensory experiences; on the other hand, it is completely in line with the boldest proposals of the new sensory marketing.

The last decade has been characterized by the gradual diffu- sion of innovative multimedia displays involving the combined use of virtual reconstructions, films and sound effects. These "new" museums that use new media in a creative way and do not hesitate to interconnect different forms of authenticity include the Civitella National Archaeological Museum of Chieti in Italy (inaugurated in 2000) and the Römer Museum of the Xanten Archaeological Park in Germany (inaugurated in 2008). These are marvellous museums, in new structures, which combine elegance of design with functionality of custom-designed exhibition spaces. They mark a new approach to museum education, with simple and effective displays designed to teach and amuse with both seriousness and lightness. The witticism of the Chieti museum, "the theatre becomes museum and the museum theatre", is emblematic of an orientation that, with the help of the new media, combines communication and spectacularization. Yet, this museum is an exception in Italy, where innovative interventions and the use of digital media are usually reserved for "events" able to benefit private financiers interested in a public success.

Nevertheless, we can also mention some excellent interventions in small local archaeological museums, whose limited size reduces the cost of multimedia displays and whose marginal geographical position requires quality interventions in order to attract visitors. This is the case, for instance, of the Lavinium Archaeological Museum of Pomezia, near Rome (inaugurated in 2005), where narrative multimedia installations, starting with the myth of Ulysses, recount the history of the territory in a very suggestive manner. This small treasure, designed by a young female architect, shows the creative potential of a generation of professionals who should be actively encouraged.

A separate discussion is reserved for museums lacking archaeological specimens and based entirely on the use of digital media. In addition to the aforesaid Hellenic Cosmos museum of Athens, distinguished by its research activities and production of virtual contents, we can mention the Virtual Archaeological Museum (MAV) of Herculaneum (inaugurated in 2008), in which ambition and innovation appear to be balanced. In line with current trends, this museum hosts all kinds of activities, from contemporary art exhibitions to a media library. Its main part is dedicated to ancient history, with virtual and multimedia reconstructions of life in Vesuvian towns. The visit, as explained on the museum's web site, "is like a plunge into history", in which "the visitor has the chance to experience a multi-sensory and emotional journey". The visit includes "a passage through a virtual blazing cloud" and an oleographic reconstruction of "an ancient treasure chest of fabulous jewels". This kind of archaeological tourism, reminiscent of Indiana Jones, is made up of adventures and treasures. This is edutainment culture in full swing and its organizers seem to fear that the word "museum" might put visitors off: "Unlike a traditional museum, visitors do not come into contact with real finds, crystallized and static, but follow a dynamic and evocative pathway through virtual reconstructions and visual interfaces which reproduce and document the realities of the past in their original form”. Intrinsically virtual on account of its hypothetical nature, the concept of "original form" shows the affinity between scientific research, which aims at returning to an interpretation favouring hypothetical and archaeological authenticity, and the cultural, and not merely touristic, need to have so-called authentic experiences. The MAV goes one step further, however, and in an attempt to capture much of contemporary culture's latent need for transcendence, passes from virtu- 
ality to mysticism. Because "it is necessary to immerse oneself in the right atmosphere", "a kind of ancestral portal is an introduction to the journey and frees our bodies in streams of connective intelligence”.

The exhibition "Teotihuacan, city of the gods" (held in Rome between 2010 and 2011) is a good example of the most recent uses of digital media: virtual reality is almost obsolete; the use of multimedia is reduced to projections of simple but extremely suggestive images, which create colourful backgrounds of strong emotional impact. For instance, in the room dedicated to human sacrifice, a projection system makes red drops of blood fall on the floor. Virtual reality and technology are no longer used to reconstruct finds or buildings, but to directly create an emotional "atmosphere" and to give concrete visual substance to the collective image of a given culture.

The same principle marked "Coliseum on Fire”, a 2010 video installation by Thyra Hiden and Pio Diaz, which, by clever use of light, created a mock fire inside the amphitheatre, recalling the fire, attributed to Nero, that destroyed Rome (even though the Coliseum was built many years later). Light shaped a collective image of ancient Rome, fashioned by sword-and-sandal movies and imbued with the voyeuristic culture of catastrophe, demanding blood and fire. According to the then Italian Ministry of Culture, this was to induce "a reflection on the fragility and the transience of man-made buildings", but actually it leads to a reflection on the fluidity of the value and identity of monuments in contemporary society.

The ever more numerous interventions of spectacularization of archaeological areas include the work begun by the famous light-designer Piero Castiglioni in the Roman Forum (in 2010). As proudly stated on the Municipality of Rome's web site, forty "Italian-made" projectors give "plastic attention" to the Forum's most important ruins with an "eco-compatible system of low energy consumption and low environmental impact”. This installation synthesizes the latest tendencies in this sector: the archaeological area is increasingly considered the key site of a city's space, able to enhance the urban context and thereby deserving of beautification interventions. The user does not stop at visiting the archaeological area but seeks the emotions aroused by the night-time visit and plays of light. The interventions not only spectacularize the area but become forms of spectacle per se, being entrusted to "archistars" and fashionable designers.

It should be underlined that these types of interventions require a low level of technology and can be realized with rather limited costs with respect to their strong publicity and attendance benefits. In this regard, the emblematic case that signalled a revolution was the intervention of the Oscar winner Dante Ferretti in Turin's Egyptian Museum. Without any modification of the collection, a simple but striking light design, aimed at emphasizing the more mysterious aspects of Egyptian culture, increased the number of visitors from 300,000 to 530,000 .

The success of these interventions is making them "fashionable” as tools of urban marketing. However, they risk remaining unrealistically ambitious activities that have difficulty being included in the policies of the territory. This is the case, for instance, of the Temple of Jupiter Axur at Terracina in Latium, where in 2007 the Municipality promoted a project of "technological spectacularization” entrusted to Carlo Rambaldi, past Oscar winner for special effects. The project, involving electronic guides with avatars and laser lighting of the monument, intelligently embodied the new video and movie-oriented trends of sensory cultural tourism but remained bogged down in the swamp of bureaucracy.

These difficulties in the public sector contrast with the efficiency shown by the private sector. In 2006, singer-songwriter Luciano Ligabue recorded a successful video-clip on the terrace of the Temple of Jupiter: a music video that helped popularize the image of this archaeological area in a much more effective way than any possible intervention of spectacularization feasible in situ.

There are also interventions of spectacularization of more traditional archaeological areas. An extremely interesting example is the site of Teotihuacan, one of the most important archaeological areas in Mexico. In 2009, the government tried to introduce a "sound and light" show called "Resplandor Teotihuacano", installing rows of tiny Philips lights on the pyramids and all along the Avenue of the Dead. This kind of intervention was a traditional one with no use of sophisticated digital media. Scholars questioned the intervention, which apparently damaged the archaeological monuments, even though the lights were (officially) installed in the parts of the monuments rebuilt during early 20th century restoration work. But the most interesting aspect was the battle against electrification waged by the local community, which defended a supposed local identity and local authenticity against political centralism and cultural globalization of archaeological tourism. The intervention of a UNO-related body led to the removal of the lights. particular case of post-modern spectacularization is the site of Newgrange in Ireland. Every year, between December 19th - 23rd, the first rays of the sun shine directly along the passage through a small opening above the entrance and briefly illuminate the burial chamber. In these five days thousands of visitors are drawn to Newgrange by the combined effect of this evocative phenomenon, blown up by the media which inevitably harp on its magical and mysterious aspects, and the irresistible force that "events" exert in a consumer society, especially if they are brief and marketed as exclusive. There is a waiting list for the occasion but it is impossible to satisfy the enormous number of requests. To satisfy the growing demand, the site's organizers, with considerable imagination and pragmatism, have held a lottery since 2000 to facilitate what is advertised as a "dramatic event”. Those who ask to be put on the Newgrange waiting list do not necessarily wish to visit the archaeological site but crave the emotional experience of the event that this site provides on those special days. The archaeological context is secondary and simply a setting. The immaterial reinvention of Newgrange goes well beyond the lottery. The sun shining into the tomb is no longer a mere tourist event or a phenomenon of mere archaeological interest; it has almost become a national event, characterized, like a true feast, by an annual recurrence. The event is often broadcast live on television and, with global outreach, on the internet. So that no one is disappointed, an electrical device makes it possible to create the effect of the solstitial illumination at any moment: at the end of the visit, the guide turns off the main lights and the system recreates the effect. The latest frontier of tourism of light is not so much the illumination of monuments as the emotional reconstruction of the non-material heritage of humanity.

\section{New Skills for a New Tourism}

Archaeological tourist attractions are characterized by a mix 
of traditional live shows, sounds and lights, and special effects borrowed from cinema. Moreover, digital technologies allow the tourist to visit the site even before leaving home or to see it as it once was, reconstructed in an entrance hall or at the exit of the archaeological area, or to visit structures re-invented in the vicinity of the site.

Common to the "new" archaeological areas is the "re-construction" of the place via an increasing use of digital media that "create" a new tourist virtual experience (Melotti, 2008). New narrations are invented from nothing via images that recount the cultural heritage with "additions" or replace it "completely" with a reality that never existed before. In this continuum, the identification with strong bonds, like national pride, becomes progressively weaker because the "play" oriented to the business of tourists prevails over the "duty" to remember the traces of ancestors we conserve for ourselves. There is a connection between the neo-realism and fluid interactivity of the videogame technologies and the 3D-virtual reality: the paper of Bruno et al. (2010) illustrates a complete methodology to create a virtual exhibition system, based on realistic high-quality 3D called MNEME, which allows the use to interact in a free and easy way with a rich collection of archaeological finds. The cultural heritage interactive 3D model is a formal "game", using also open source and free software (Guarnieri, Pirotti, \& Vettore, 2010), in the fluid "play" of the tourist virtual experience.

There has arisen a new interdisciplinary knowledge that interprets the traces of the past and the interpretations of specialists, such as professional archaeologists. It re-invents the memories of the past embodied in archaeological finds with presentations and with narrative and visual representations in which something is re-invented to amaze and to "play", as if the visitor was really an art or archaeology professional; in reality, however, it has a ludic and liminal role, without the search for sincere authenticity. Each initiative "enhances" the archaeological area with new images truer than the truth: traditional printed guides showing the place in its ancient splendour, reconstructed as it once was and compared with the present-day ruins; interactive touchscreens showing details of a fresco invisible to the naked eye; special effects, according to the use initiated by the French son et lumière method, etc.

The heritage of the senses continues to have a very traditional function typical of tourism, from the Grand Tour to mass sightseeing, including the romantic "gaze" with its celebrations (Urry, 1990; Melotti, 2011). The "case” of the Byzantine heritage at Thessaloniki in Greece demonstrates that the organizers have shared the national character anchored to a "golden" past (Chronis, 2006). However, collective memory as a praxis incorporated in multi-sensory experience is a legacy of mass tourism and is useful for enduring forms of national pride. This can motivate the enhancement of the heritage but it is only an "as if", a type of "play", because the true ambition is to attract multi-sensory cultural tourists from all parts of the world.

"Strong" categories of collective identity (contrasted to fragmentation or historical discontinuity) and of authenticity (contrasted to falseness) are not effective in explaining the prevalence of "play", "fantasy" and "entertainment" that characterize the now consolidated global mobility of cosmopolitan visitors who make the journey serious leisure (Stebbins, 2007). This is tourism that "crosses" borders and generates new attractions no longer conforming to strong traditional affiliations, such as national pride or "memory" of a past that should give meaning to the present. The visual culture of archaeological areas gives rise to cosmopolitan knowledge and skills in the management of technologies, hybridizing them with tourism. Satisfying the users of virtual reality also increases the symbolic, and thus economic, value of the de-territorialized archaeological area.

\section{Beyond Critical Theories}

The re-invention of archaeological areas via virtual reality is part of a trend of contemporary capitalism that uses visual culture as a productive factor. The virtual reality of digital media is part of the entertainment industry, which breaks down the borders between disciplines, types of knowledge and spatial practices to create a new mix of knowledge. This is a post-Ford industry dominated by the assembly line, which fuses several sectors of the economy: cinema, show business, tourism, publishing, design, games, sport, etc. The connections "between" and "across" in various visual practices give an innovative meaning to the recreational and cultural experience. This fusion is not "liquid", because it is accomplished by powers with cultural hegemony. The entertainment industry, even if it shows a friendly face, is no less structured and pervasive than the factory and the modern state.

The organization of the work and the skills is interdisciplinary and requires creative groups constituted in a selective manner. It does not give rise to the de-skilling of McDonaldization (Ritzer, 1996). The creative groups form professional elites practising a new cultural hegemony in heritage and archaeological areas, with the showing off of non-ephemeral realizations that require incremental knowledge and cross-fertilization of humanistic and technological disciplines, as well as professionalisms with up-skilling in the interdisciplinary treatment of various expertises. It is necessary, for instance, to know how to integrate the knowledge of classical studies, the creativeness of virtual reality and the marketing of archaeological areas. The Disney figure of the imagineer (engineer of images) is an example of these highly skilled professionals. On the other hand, choreographies and technological installations require "narrative metaphors” (Missikoff, 2005), which in turn presuppose a mixture of creativity and technological, linguistic, pedagogical, psychological and advertising skills. Rambaldi, the already mentioned Oscar winner for special effects, has formed an interdisciplinary team in Rimini, Italy, to fuse cinematic inventions with virtual realities that interpret the history of archaeological areas, and he has also established companies with marketing management skills for tourism management of sites. Therefore, skills of advanced knowledge workers can be identified in re-invented archaeological areas. In this context, archaeologists and managers can form collaborative partnerships to draw economic resources from the polysensorial tourism market to create a consensus necessary to make the tourist destination unique in terms of quality and appeal.

Talking of the "Disneyfication" of archaeological areas mainly seems an aesthetic cultural criticism by somewhat snobbish intellectuals (Löfgren, 1999; Urbain, 1991). In parallel, worries about the environmental impact of virtual reality often appear excessive. In fact, the deterioration of ancient monuments is due to causes quite different from a touchscreen or from a virtual head that speaks and tells stories about the place to entertain tourists or from an innovative GPS-based visual guide. 


\section{Polysensoriality vs Staged Authenticity and Tourist Gaze}

Virtual and experiential archaeology is not only the empowerment of traditional tourism communication, included in an original promotional mix. It is not only a new means of publicity added to those of the old media. It is not only a further opportunity to spread formal knowledge, located in the head of archaeologists as specialists of the logos (edu-entertainment). It is not only the materialization of immaterial knowledge, related mainly to visual culture, which generates a new experience and stimulates both the senses and the intellect (ludic polysensoriality). It is all of these things together.

The new polysensorial gaze is not based on seeing (the tourist gaze of Urry, 1990) but rather on re-seeing what was imagined through the old and new media before the start of the journey, when the tourist was a television or cinema viewer or the reader of a cartoon or the user of a film with contents generated by an opinion leader or a friend who included it in the blog. The place has already been seen at the cinema or in the blog of an online community and it has already been narrated via word-of-mouth and intermittent discussions with interested people or hobbyists. The journey is a re-seeing: a re-living of the experience elaborated with the imagination and now created by enterprises that also operate in tourism to satisfy the expectations and materialize the mental maps of tourists. The possibility of visiting an archaeological area online before actually visiting it is one aspect of a general trend that, for instance, allows the tourist to use the online visit to choose the hotel room most suitable for his needs. The manager of the archaeological area and the hotel manager are simply stimulated to use the web marketing video to adapt the offer to the new tourist, self-confident and competent in mixing the services by himself.

Once the clear distinction between authenticity and representation disappears, the clear distinction between collective gaze and romantic gaze and between ordinary and extraordinary theorized by Urry also disappears. The representations are linked to personal relationships, which provide moments of happiness and thus of authenticity co-existing in the gaze that intermittently alternates ordinary and extraordinary in anchorplaces to be visited during the journey. Hence, it is not possible to draw a clear distinction between authentic extraordinary objects, sought by the tourist because they are unique, and nonauthentic ordinary representations, consisting of services that commercialize culture. There is no longer a distinction, but rather mixture, pastiche, flows and mobility.

The authentic experience in archaeological areas does not involve the depth of MacCannell's back region (1976) or Urry's romantic gaze, but the ability to play with hybridizations of knowledge in order to learn both the historicity of the specimens (journey into the past) and the new visual arts through archaeology as a pretext (journey into the change induced by contemporary inventions).

Case studies have shown that the actors in archaeological areas enhanced by media (organizers of the offer, commercial intermediaries, technologists, users, etc.) are not nostalgic for heritage and, more in general, for cultural tourism that journeys to the past as if it were better than the present, to experience an ontological authenticity represented at different levels of "sincerity" and "truth" in the objects. The joyous post-modern reinvention shatters the "ritual respect" and "celebration" of archaeological finds as transcendences, which have survived urbanism and transformative modernity that forgets the past in the search of the new. Instead, the past is a resource for relational authenticity to be experienced in the present, re-inventing memories to be happy here and now without reactive nostalgia. Hence, the sale of objects and experiences creates a relational authenticity aimed at the construction of friendly, intermittent, playful networks. They are the consequence of collaborative intentionality, of free choices and of hybridization of cultures and differences. The authenticity is relational, knowingly invented and measured on the basis of the levels of happiness people experience by participating in the multimedia play of post-modern cultural tourism. The authenticity is in the relationships that it generates and that are recognized as inter-subjective experiences in the interpretation of memories.

Conserved from MacCannell is the idea of "authenticity”, but this is understood as a resource fused with other cultural resources. Conserved from Urry is the idea that archaeological areas constitute "moorings" (Hannam, Sheller, \& Urry, 2006) to the mobility of flows, information, ideas and people; they are meeting places that generate moments of happiness to recall without nostalgia but to repeat with new trips, including them in a flow that goes beyond the distinctions between work and leisure and the life cycle of each tourist.

\section{Virtual Archaeological Areas and the Theory of Hyper-Tourism}

In archaeological areas we can observe economic and cultural powers that use the polysensorial immaterial (information, images, sounds, lights, etc.) as a productive resource of the post-modern economy. Fantasy is made real.

In the Taylor-Ford economy and in industrial tourism the one best way was sought with standardized models (e.g. management of the sightseer's gaze within the all-inclusive tour). In the post-modern economy of virtual entertainment there are various solutions: creativity and interdisciplinarity are encouraged and the rules of management are negotiable, based on free collaborative partnerships among stakeholders interested in exchanging knowledge, skills and services. For tourism, this leads to the invention of polysensorial experiences via quality inventions and services that form paid cultural resources or new products for an active and experiential tourist.

The theory of hyper-tourism (Costa \& Martinotti, 2003) explains the change without reference to apocalyptic theses on contemporary capitalism. It partly replaces the thesis of staged authenticity (MacCannell, 1976) and the phenomenology of the tourist gaze (Urry, 1990). Hyper-tourism does not require MacCannell's distinction between back and front region or Urry's distinction between ordinary and extraordinary: virtual reality is a type of play knowingly organized and chosen by users to experience the fantasy city (Hunnigan, 1998), which extends its innovations to archaeological areas. Experiences of authenticity and extraordinariness are invented by actors perfectly aware that "this is play" and that hyper-tourism is an "as if" (from 3D reconstruction to virtual reality). The archaeological is a place to play and a place in play (Sheller \& Urry, 2004).

The comparative analysis of archaeological areas demonstrates that the trend toward hybridization of types of knowledge is at the beginning and is probably destined to spread with new proposals. The development is non-linear. The spatial practices of digital hyper-tourism are controversial. Our analysis has revealed the substantial difference between archaeo- 
logical areas managed with openness to the diversity and plurality of "arguments competing" to define what is beautiful and what is ugly, what is useful and what is harmful, what gives happiness and what gives unhappiness, and archaeological areas managed in a hierarchical manner because intellectual elites (archaeologists, for instance) seek to be the unique interpreters of the place and refuse the hybridization of types of knowledge, among which digital media which might ruin the "purity" of the area. In the former case, the management contributes to enhancement via virtual reality and uses its new professionals as interpreters of the culture of archaeological areas. Through regulations, the scientific directors adopt rules and behaviours and demonstrate trust in the fact that there are neither losers nor winners, all the actors can "win together" with initiatives that "increase" the meanings of the place. In the latter case, many projects remain unrealized because the purist elite has imposed vetoes and wishes to drive away the operators of digital-mediated experience. Archaeologists are afraid of losing their exclusive right to the place.

This paper demonstrates that in archaeological areas it is possible to apply a theory of regulation based on a bottom-up model and on collaborative partnerships among humanist intellectuals, digital media technologists (from 3D reconstruction to virtual reality) and entertainment entrepreneurs.

\section{Acknowledgements}

The paragraph 1 has been written by both authors; the paragraphs 2, 3 and 4 by Marxiano Melotti; the paragraphs 5, 6, 7 and 8 by Nicolò Costa.

\section{REFERENCES}

Adler, J. (1989). Origins of sightseeing. Annals of Tourism Research, 16, 7-29. doi:10.1016/0160-7383(89)90028-5

Avgouli, M. (1994). The first Greek museums and national identity. In E. E. S. Kaplan (Ed.), Museums and the making of "ourselves". The role of the objects in national identity (pp. 246-265). New York: Leicester University Press.

Bauman, Z. (2000). Liquid modernity. Cambrige: Polity Press.

Bruno, B., Bruno, S., De Sensi, G., Luchi, M.-L., Mancuso, S., \& Muzzupappa, M. (2010). From 3D reconstruction to virtual reality. A compete methodology for digital archaeological exhibition. Journal of Cultural Heritage, 11, 42-49. doi:10.1016/j.culher.2009.02.006

Chronis, A. (2006). Heritage of the senses. Collective remembering as an embodied praxis. Tourist Studies, 6, 267-296. doi:10.1177/1468797607076674

Clack, T., \& Brittain, M. (2007) Archaeology and the media. Walnut Creek, CA: Left Coast Press.

Costa, N. (2003). La città dell'ospitalità spettacolarizzata: un'Analisi comparata dell'entertainment city. In Ministero delle Attività Produttive-Direzione Generale per il Turismo, Il pensiero e la scienza nel turismo italiano (pp. 157-165). Roma: Direzione generale per il turismo.

Costa, N. (2005a). I professionisti dello sviluppo turistico locale. I sistemi turistici locali come opportunità di lavoro. Milano: Hoepli.

Costa, N. (2005b). La città dell'iperturismo. Milano: Cuesp.

Costa, N., \& Martinotti, G. (2003). Sociological theories of tourism and regulation theory. In L. M. Hoffman, S. S. Fainstein, \& D. R. Judd (Eds.), Cities and visitors. Regulating people, markets, and city space (pp. 53-71). London: Blackwell.

Crouch, D., \& Lubben, L. (2003) Visual culture and tourism. Oxford,
New York: Berg.

Crouch, D., \& Desforges, L. (2003). The sensuous in the tourist encounter. Introduction: The power of the body in tourist studies. Tourist Studies, 3, 5-22. doi:10.1177/1468797603040528

Guarnieri, A., Pirotti, F., \& Vettore, A. (2010). Cultural heritage interactive 3D models on the web: An approach using open source and free software. Journal of Cultural Heritage, 11, 350-353. doi:10.1016/j.culher.2009.11.011

Guttentag, D. A. (2010). Virtual reality: Applications and implications for tourism. Tourism Management, 31, 637-651. doi:10.1016/j.tourman.2009.07.003

Hannam, K., Sheller, M., \& Urry, J. (2006). Mobilities, immobilities and moorings. Mobilities, 1, 1-22. doi:10.1080/17450100500489189

Hannigan, J. (1998), Fantasy city: Pleasure and profit in the postmodern metropolis. London: Routledge.

Joy, A., \& Sherry, J. E. (2003). Speaking of art as embodied imagination: A multisensory approach to understanding aesthetic experience. Journal of Consumer Research, 30, 259-282. doi:10.1086/376802

Löfgren, O. (1999). On holiday: A history of vacationing. Berkeley, CA: University of California Press.

MacCannell, D. (1976). The tourist. A new theory of the leisure class. New York: Schocken Books.

McCabe, S., \& Foster, C. (2006). The role and function of narrative in tourist interaction. Journal of Tourism and Cultural Change, 4, 194-215. doi:10.2167/jtcc071.0

Melotti, M. (2003). Un jour à Pompéi avec “Lifeplus”. Réalité virtuelle entre archéologie et tourisme. In Association Monégasque pour la Connaissance des Arts 2003, Nouvelles technologies au service de la protection du patrimoine méditerranéen et de la diffusion de sa culture (pp. 139-151).

Melotti, M. (2004). Turismo tra mito e realtà virtuale. Il caso di Olimpia da Pausania ad “Archeoguide”. Turistica, 9, 89-98.

Melotti, M. (2006). Nuove tecnologie per il turismo archeologico. In R. Bisiani, \& D. Diamantini (Eds.), Mobilità e società dell'informazione. Milano: Guerini.

Melotti, M. (2008). Turismo archeologico. Dalle piramidi alle veneri di plastica. Milano: Bruno Mondadori.

Melotti, M. (2008b). Nascita di un mito. Il turismo a Pompei tra amore e morte. In L. Jacobelli (Ed.), Pompei, la costruzione di un mito. Arte, letteratura e aneddotica nell'immagine turistica di Pompei (pp. 95-116). Roma: Bardi.

Melotti, M. (2011). The plastic venuses. Archaeological tourism and post-modern society. Newcastle upon Tyne: Cambridge Scholars.

Missikoff, O. (2006). Assessing the role of digital technologies for the development of cultural resources as socio-economic assets. In I. Russel (Ed.), Images, representations and heritage. Moving beyond modern approaches to archaeology (pp. 139-159). New York: Springer.

Pine, J., \& Gilmore, J. (1999). The experience economy. Boston, MA: Harvard Business School Press.

Pujol, L. (2004). Arqueologia, museus i realitat virtual. Digithum UOC. Revista digital d'umanitats, 6 .

Ritzer, G. (1996). The Mcdonaldization of society. Thousand Oaks, CA: Pine Forge Press.

Sheller, M., \& Urry, J. (2004). Tourism mobilities. London, New York: Routledge.

Stebbins, R. A. (2007). Serious leisure. New Brunswick, NJ: Transaction.

Swain, H. (2007). An introduction to museum archaeology. Cambridge, MA: Cambridge University Press.

Urbain, J.-D. (1991). L'idiot du voyage. Histories de touristes. Paris: Plon.

Urry, J. (1990). The tourist gaze: Leisure and travel in contemporary societies. London: Sage.

Wang, N. (2000). Tourism and modernity. A sociological analysis. Oxford: Pergamon Press. 